\title{
Characteristic Risk Factors Associated with Planned versus Impulsive Suicide Attempters
}

\author{
Jaeha Kim, Kang-Sook Lee ${ }^{2}$, Dai Jin Kim ${ }^{3}$, Seung-Chul Hong ${ }^{4}$, Kyoung Ho Choi ${ }^{5}$, Youngmin $\mathrm{Oh}^{5}$, \\ Sheng-Min Wang', Hae-Kook Lee', Yong-Sil Kweon', Chung Tai Lee', Kyoung-Uk Lee \\ Departments of ${ }^{1}$ Psychiatry and ${ }^{5}$ Emergency Medicine, Uijeongbu St. Mary's Hospital, College of Medicine, The Catholic University of \\ Korea, Seoul, ${ }^{2}$ Department of Preventive Medicine, Catholic Industrial Medical Center, College of Medicine, The Catholic University of \\ Korea, ${ }^{3}$ Department of Psychiatry, Seoul St. Mary's Hospital, College of Medicine, The Catholic University of Korea, Seoul, ${ }^{4}$ Department \\ of Psychiatry, St. Vincent's Hospital, College of Medicine, The Catholic University of Korea, Seoul, Korea
}

\begin{abstract}
Objective: The present study aimed to investigate predictors for planned suicide attempters.
Methods: This study included 1,003 patients who attempted suicide and visited emergency department. They were divided into two groups, planned suicide attempters (SAs; $n=133$ [13.3\%]) and impulsive SAs ( $n=870,[86.7 \%]$ ), and the demographic variables, clinical characteristics, factors related to suicide, and psychiatric resources of the groups were compared.

Results: Major depressive disorder and substance use disorders were more common among planned SAs than among impulsive SAs. Additionally, the planned SAs were older, more likely to be divorced, separated or widowed, and more likely to have comorbid medical illnesses, severe depression, higher suicidality, and self-blaming tendencies than the impulsive SAs. Financial problems and physical illnesses were more common in planned SAs but interpersonal conflicts were more frequent in impulsive SAs. Planned SAs had fewer previous suicide attempts but these were more serious suicide attempts. The presence of the hope to die, a written will, and suicidal ideation of a repetitive, intense, and continuous nature were predictive of planned SAs. Conclusion: The present findings demonstrated that planned SAs had more severe psychopathology and medical illnesses than impulsive SAs. Therefore, screening for depression, substance use disorders, and suicidal plans among old and medically ill patients may be important for preventing suicide attempts.
\end{abstract}

KEY WORDS: Suicide; Attempted suicide; Impulsive behavior; Suicide plan.

\section{INTRODUCTION}

Suicide is a major cause of mortality worldwide as well as an important public health problem. ${ }^{1,2)}$ This is particularly evident in South Korea, where suicide is the fourth leading cause of death and the estimated suicide mortality is 29.1 per 100,000 people, which was the highest among the countries of the Organization for Economic Cooperation and Development (OECD) in 2012 (average rate, 12.1 per 100,000 people $^{3)}$ ).

The planning of a suicide is often considered to be part of the progression of suicidal ideation and the last stage prior to a suicide attempt. ${ }^{4}$ Additionally, as one of the im-

\footnotetext{
Received: August 4, 2015 / Revised: September 30, 2015 Accepted: October 4, 2015

Address for correspondence: Kyoung-Uk Lee, MD, PhD Department of Psychiatry, Uijeongbu St. Mary's Hospital, College of Medicine, The Catholic University of Korea, 222 Banpo-daero, Seocho-gu, Seoul 06591, Korea

Tel: +82-31-820-3609, Fax: +82-31-847-3630

E-mail: mindcure@catholic.ac.kr
}

pending signs of suicide, the creation of a suicide plan prior to the actual act is considered to be an important marker of its occurrence. ${ }^{5)}$ The recognition of a suicide plan is important because the prevention of a suicide attempt requires different preventative strategies depending on whether such a plan is present. ${ }^{6}$ ) Moreover, because the most serious suicide attempters (SAs) tend not to share their plan voluntarily, $\left.{ }^{6}\right)$ it is important to recognize its risks and to screen for a plan. Because planned and impulsive SAs may be associated with different characteristics, a clarification of the particular factors associated with these populations would be helpful for the prevention of suicides.

Several studies have investigated the differences between planned SAs and impulsive SAs. Planned SAs are associated with higher levels of depression ${ }^{6,7)}$ and greater lethality ${ }^{8,9}$ than impulsive SAs as well as with variables such as older age, ${ }^{9)}$ severe mental illness, ${ }^{10)}$ and an intense intent to die. ${ }^{11)}$ However, these findings are inconsistent among studies and require further examination. For exam-

(a) This is an Open-Access article distributed under the terms of the Creative Commons Attribution Non-Commercial License (http://creativecommons.org/licenses/by-nc/4.0) which permits unrestricted non-commercial use, distribution, and reproduction in any medium, provided the original work is properly cited. 
ple, the male gender was once considered to correlate with planned suicide attempts ${ }^{12}$ but a multi-site European study sponsored by the World Health Organization failed to demonstrate significant gender-related differences in the planning of attempts. ${ }^{13)}$ Similarly, the reported rates of planned suicidal acts vary from $22 \%{ }^{14)}$ to $64 \%{ }^{15)}$, which suggests that there is a marked heterogeneity in the reported findings.

As mentioned above, several controversies and discrepancies remain regarding the findings of studies investigating suicide attempts, which may be due, at least in part, to differences in the studied populations and research designs. In fact, many previous studies were community-based ${ }^{15-17)}$ and were conducted at a relatively late date after the suicidal action, which may have resulted in considerable recall bias. Additionally, because the data were primarily obtained via self-report, the denial and under-reporting of suicide attempts by the subjects may have also affected the results. Some studies conducted interviews with subjects who were admitted to the emergency department (ED) after attempting to commit suicide ${ }^{7,8)}$ and these studies may minimize the recall bias by obtaining information soon after the attempt. However, the findings of these studies may be difficult to generalize due to small sample sizes ${ }^{18)}$ and the inclusion of special populations. ${ }^{19)}$ Furthermore, some of the studies conducted psychiatric evaluations at times relatively long after the index attempt and, thus, may not accurately represent the status of patients at the time of the actual suicide attempt. ${ }^{20,21)}$

Thus, the primary goals of the present study were to investigate the characteristics of planned SAs compared to impulsive SAs and to investigate the risk factors associated with planned SAs to determine information that would aid in the treatment and prevention of suicide. To accomplish this, the present study enrolled patients who visited our ED following a suicide attempt and who underwent psychiatric interviews and assessments performed by psychiatry residents within 48 hours of the attempt in order to minimize recall bias. Additionally, a comprehensive analysis of the risk factors related to suicide attempts was conducted using a sufficient sample size.

\section{METHODS}

\section{Participants}

The present study included patients who attempted suicide and then visited the EDs of Uijeongbu St. Mary's Hospital, Seoul St. Mary's Hospital, or St. Vincent's Hospital between December 2009 and December 2013.
Patients were eligible if they were confirmed as a SA by the patient him/herself or if they denied attempting suicide but objective information from their guardians or rescuers confirmed that they had attempted suicide. A total of 1,006 participants agreed to be interviewed by a psychiatric resident in the ED.

The present study was approved by the institutional review boards of the Catholic University of Korea, Uijeongbu St. Mary's Hospital, Seoul St. Mary's Hospital, and St. Vincent's Hospital (IRB file No. XC12RIME0141).

\section{Measures}

A comprehensive psychiatric interview and the Brief Emergency Room Suicide Risk Assessment (BESRA) were administered to all 1,006 participants. The BESRA was developed by our research team to aid in the rapid and accurate decision-making of clinicians in the ED by assessing a patient's risks of present suicide attempts and repeated suicide attempts. ${ }^{22,23)}$ This measure assesses the demographic variables and clinical characteristics of the patient, the factors related with the presenting suicide behaviors, and various individual psychiatric resources (see Supplementary material attached to the electronic version of this paper ${ }^{24)}$. Additionally, this tool assesses detailed information regarding the presenting suicide attempt including established suicide risk factors and the risk/rescue-rating scales, of which the reliability and validity have been confirmed. ${ }^{25)}$ The risk/rescue-rating scales consist of 10 items; five items assess risk factors and five items assess rescue factors. ${ }^{26)}$ A higher risk-rating score indicates that the patient's suicide attempt was more serious whereas a higher rescue-rating score indicates that the patient committed a less serious and more rescuable suicide attempt.

The suicide plan was judged using a systematic suicide interview performed by trained psychiatry residents. The presence of a will, preparation of method, and planning of the date of the attempt associated with the index attempt were regarded as indicators of a planned suicide attempt. Psychiatric diagnoses were made based on the criteria of the Diagnostic and Statistical Manual of Mental Disorders, 4th edition, text revision (DSM-IV-TR; American Psychiatric Association, 1994) following an intensive diagnostic interview that was performed by trained psychiatry residents. To ensure the reliability of the diagnoses and psychiatric evaluations, consensus meetings were conducted biweekly.

\section{Statistical Analysis}

Of the initial 1,006 patients assessed for the present 
study, the data of 1,003 patients were analyzed following the exclusion of three patients due to missing data. The patients were divided into two groups, planned SAs and impulsive SAs, and $t$-tests and chi-squared analyses were performed to assess the study variables. $p$-values $<0.05$ were considered to indicate statistical significance and the variables that were within this threshold were selected for inclusion in a multivariate logistic regression analysis (MLRA). The variables were entered into the MLRA using a backward stepwise method and all missing values were excluded from the analyses. All statistical analyses were conducted using Statistical Analysis System software package, version 9.2 (SAS Institute Inc., Cary, NC, USA).

\section{RESULTS}

\section{Comparisons of Psychiatric Diagnoses between the Planned and Impulsive SAs}

A total of 133 participants (13.3\%) had formulated a plan of suicide (planned SAs) and 870 participants (86.7\%) attempted suicide impulsively (impulsive SAs) (Table 1). The most common psychiatric diagnosis in both groups was major depressive disorder $(n=535,47.1 \%)$ but the planned SAs were more frequently diagnosed with major depressive disorder than the impulsive SAs $\left(\chi^{2}=\right.$ $24.90, p<0.001$ ). Additionally, the prevalence rates of alcohol or other substance use disorders were significantly higher in the planned SA group $\left(\chi^{2}=4.46, p=0.035\right)$ whereas adjustment disorder was more common in the impulsive SA group $\left(\chi^{2}=24.02, p<0.001\right)$.

\section{Comparisons of the Demographic and Clinical Factors}

The mean age of the planned SA group was signifi-

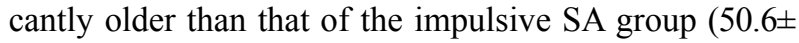
18.6 vs. $42.6 \pm 17.8$, respectively; $t=4.79, p<0.001$ ) (Table 2 ) but there was no difference in the gender ratio. Divorced/ separated or widowed patients were more common in the planned SA group than in the impulsive SA group (divorced or separated: 22 [16.5\%] and 105 [12.1\%], respectively; widowed: 21 [15.8\%] and 79 [9.1\%], respectively; $\chi^{2}=$ $10.29, p=0.016$ ). With respect to clinical characteristics, the planned SA group had significantly more comorbid medical illnesses and more severe depressive symptoms than the impulsive SA group (comorbid illness: $\chi^{2}=10.20$, $p=0.001$; severe depression: $\chi^{2}=43.84, p<0.001$ ).

\section{Comparisons of Factors Related to Presenting Suicide Behavior}

The planned SA group had significantly more repetitive/ severe/continuous suicidal ideation than the impulsive SA group $\left(\chi^{2}=72.23, p<0.001\right)$ as well as more agitation and feelings of hopelessness/helpless, and a greater hope to die than the impulsive SA group (agitation: $\chi^{2}=12.04$, $p=0.001$; hopelessness/helplessness: $\chi^{2}=39.95, p<0.001$; hope to die: $\left.\chi^{2}=199.03, p<0.001\right)$. Interpersonal stress/ conflict was the most common precipitating stressor prior to a suicide attempt for both groups $(n=626,62.4 \%)$ but fi-

Table 1. The comparison of psychiatric diagnoses between planned and impulsive suicide attempters

\begin{tabular}{|c|c|c|c|c|}
\hline Psychiatric diagnosis & $\begin{array}{l}\text { Planned attempters } \\
\qquad(n=133)\end{array}$ & $\begin{array}{l}\text { Impulsive attempters } \\
\qquad(\mathrm{n}=870)\end{array}$ & $\begin{array}{c}\text { Statistics } \\
\text { (chi-square) }\end{array}$ & $p$ value \\
\hline Major depressive disorder & & & & $<0.001$ \\
\hline Present & $99(66.0)$ & $436(44.2)$ & 24.90 & \\
\hline Absent & $51(34.0)$ & $551(55.8)$ & & \\
\hline Bipolar depression & & & & 0.402 \\
\hline Present & $2(1.3)$ & $24(2.4)$ & 0.71 & \\
\hline Absent & $148(98.7)$ & $963(97.6)$ & & \\
\hline Schizophrenia and other psychotic disorder & & & & 0.145 \\
\hline Present & $8(5.3)$ & $30(3.0)$ & 2.12 & \\
\hline Absent & $142(94.7)$ & $957(97.0)$ & & \\
\hline Adjustment disorder & & & & $<0.001$ \\
\hline Present & $1(0.7)$ & $157(15.9)$ & 24.02 & \\
\hline Absent & $149(99.3)$ & $830(84.1)$ & & \\
\hline Anxiety disorder & & & & 0.859 \\
\hline Present & $1(0.7)$ & $12(1.2)$ & 0.03 & \\
\hline Absent & $149(99.3)$ & $975(98.8)$ & & \\
\hline Alcohol and other substance use disorder & & & & 0.035 \\
\hline Present & $14(9.3)$ & $50(5.1)$ & 4.46 & \\
\hline Absent & $136(90.7)$ & $937(94.9)$ & & \\
\hline
\end{tabular}

Values are presented as number (\%).

Total numbers of diagnoses for each group does not sum up to numbers of patients, because multiple diagnoses were allowed. 
Table 2. The difference of demographic and clinical factors between impulsive and planned attempters

\begin{tabular}{|c|c|c|c|c|}
\hline Variable & $\begin{array}{l}\text { Planned attempters } \\
\qquad(n=133)\end{array}$ & $\begin{array}{l}\text { Impulsive attempters } \\
\qquad(\mathrm{n}=870)\end{array}$ & $\begin{array}{c}\text { Statistics } \\
\text { († or chi-square) }\end{array}$ & $p$ value \\
\hline Demographic data & & & 4.79 & $<0.001$ \\
\hline Age $(y r)$ & $50.6 \pm 18.6$ & $42.6 \pm 17.8$ & & \\
\hline Marital status & & & 10.29 & 0.016 \\
\hline Married & $65(48.9)$ & $450(51.7)$ & & \\
\hline Single & $25(18.8)$ & $236(27.1)$ & & \\
\hline Widowed & $21(15.8)$ & $79(9.1)$ & & \\
\hline Divorced or separated & $22(16.5)$ & $105(12.1)$ & & \\
\hline \multicolumn{5}{|l|}{ Clinical psychiatric data } \\
\hline Comorbid medical illness & & & 10.20 & 0.001 \\
\hline Present & $56(42.1)$ & $247(28.5)$ & & \\
\hline Absent & $77(57.9)$ & $621(71.5)$ & & \\
\hline Severity of depression & & & 43.84 & $<0.001$ \\
\hline Mild & $2(1.5)$ & $113(13.0)$ & & \\
\hline Moderate & $32(24.1)$ & $368(42.3)$ & & \\
\hline Severe & $99(74.4)$ & $389(44.7)$ & & \\
\hline
\end{tabular}

Values are presented as mean \pm standard deviation or number (\%).

nancial problems and physical illnesses were more frequent in the planned SA group (financial problems: $\chi^{2}=$ 8.40, $p=0.004$; physical illnesses: $\chi^{2}=21.44, p<0.001$ ) whereas interpersonal stress/conflict was more frequent in the impulsive SA group $\left(\chi^{2}=25.00, p<0.001\right)$.

The planned SA group had fewer lifetime suicide attempts than the impulsive SA group $(1.4 \pm 0.8$ and $1.7 \pm 1.3$, respectively; $t=2.59, p=0.010)$ and a higher medical severity score ( $3.3 \pm 1.1$ and $2.9 \pm 1.1$, respectively; $t=4.10$, $p<0.001)$; in addition, individuals in this group were more likely to attempt suicide in a riskier and less rescuable way (total risk score: $9.0 \pm 1.9$ vs. $8.03 \pm 1.91$, respectively; $t=5.35, p<0.001$; total rescue score: $11.52 \pm 2.2$ vs. $12.9 \pm 1.85$, respectively; $t=7.55, p<0.001$ ). Although the most common suicide method was a drug overdose in both groups $(n=778,77.6 \%)$, the planned SA group was more likely to choose carbon monoxide (CO) intoxication than the impulsive SA group $\left(\chi^{2}=3.37, p=0.072\right)$ (Table 3).

\section{Risk Factors Predicting Planned Suicide Attempts}

The MLRA revealed that the hope to die (odds ratio [OR], 7.29; 95\% confidence interval [CI], 4.52-11.76), the presence of a will (OR, 4.42; 95\% CI, 2.76-7.08), and the repetitive/intense/continuous nature of suicidal ideation (OR, 3.98; 95\% CI, 2.29-6.91) significantly predicted planned suicide attempts. Additionally, a higher number of lifetime suicide attempts (OR, 0.63; 95\% CI, 0.47-0.84) and higher total rescue rating scores (OR, 0.80; 95\% CI, 0.72-0.90) served as factors against planned attempts (Table 4).

\section{DISCUSSION}

The present study aimed to investigate the characteristics associated with planned SAs relative to impulsive SAs and to examine the factors that would predict a planned suicide attempt. In agreement with previous findings, ${ }^{7-10)}$ planned SAs were older than impulsive SAs and exhibited more serious clinical profiles such as more severe depression, self-blaming tendencies, and hopelessness. Planned SAs had a high risk of completed suicide that was similar to the risks of more severe medical consequences and choosing more lethal suicide methods than impulsive SAs. Furthermore, the logistic regression analysis showed that the risk factors that predicted a planned suicide attempt included intent (hope) to die, presence of a will, and suicidal ideation of a repetitive/intense/continuous nature.

To the best of our knowledge, the present study is the largest that compared the differences between planned and impulsive SAs who visited an ED after attempting suicide. The large amount of data that was obtained allowed for the analysis of newly identified factors that were related to planned suicidal behaviors. Additionally, the evaluation of patients who were recruited immediately after attempting suicide in an ED resulted in the minimization of the possibility of denial, under-reporting, or recall bias, and allowed for reliable psychiatric diagnoses and medical evaluations by trained psychiatric doctors.

Although the present study found that the prevalence of impulsive SAs was much higher than that of planned SAs, which corresponds to the findings of previous studies, ${ }^{19,27-29)}$ other studies have reported opposite results. ${ }^{11,15,30)}$ However, these discrepancies may have been due to the meth- 
Table 3. The comparison of factors related with the presenting suicide behaviour between planned and impassive suicide attempts

\begin{tabular}{|c|c|c|c|c|}
\hline Variable & $\begin{array}{l}\text { Planned attempters } \\
\qquad(n=133)\end{array}$ & $\begin{array}{l}\text { Impulsive attempters } \\
\qquad(\mathrm{n}=870)\end{array}$ & $\begin{array}{l}\text { Statistics } \\
\text { († or chi-square) }\end{array}$ & $p$ value \\
\hline Nature of suicide idea & & & 72.23 & $<0.001$ \\
\hline Frequent/severe/continuous & $111(83.5)$ & $370(42.5)$ & & \\
\hline Rare/mild/transient & $22(16.5)$ & $499(57.4)$ & & \\
\hline Agitation & & & 12.04 & 0.001 \\
\hline Present & $73(55.3)$ & $341(39.3)$ & & \\
\hline Absent & $57(43.2)$ & $508(58.6)$ & & \\
\hline Hopeless/helpless & & & 39.95 & $<0.001$ \\
\hline Present & $122(92.4)$ & $560(64.6)$ & & \\
\hline Absent & $9(6.8)$ & $291(33.6)$ & & \\
\hline Will & & & 89.77 & $<0.001$ \\
\hline Present & $67(51.5)$ & $133(15.6)$ & & \\
\hline Absent & $63(48.5)$ & $719(84.4)$ & & \\
\hline Suicide for what & & & 199.03 & $<0.001$ \\
\hline Hope to die & $98(74.8)$ & $148(17.1)$ & & \\
\hline Hope to change & $33(25.2)$ & $702(81.3)$ & & \\
\hline Medical severity & $3.29 \pm 1.1$ & $2.89 \pm 1.1$ & 4.10 & $<0.001$ \\
\hline Total risk score & $9.0 \pm 1.9$ & $8.03 \pm 1.91$ & 5.35 & $<0.001$ \\
\hline Total rescue score & $11.52 \pm 2.2$ & $12.9 \pm 1.85$ & 7.55 & $<0.001$ \\
\hline \multicolumn{5}{|l|}{ Precipitating events } \\
\hline Interpersonal conflict/stress & & & 25.0 & $<0.001$ \\
\hline Present & $57(42.9)$ & $569(65.4)$ & & \\
\hline Absent & $76(57.1)$ & $301(34.6)$ & & \\
\hline Financial problems & & & 8.40 & 0.004 \\
\hline Present & $36(27.1)$ & $146(16.8)$ & & \\
\hline Absent & $97(72.9)$ & $724(83.2)$ & & \\
\hline Physical illnesses & & & 21.44 & $<0.001$ \\
\hline Present & $33(24.8)$ & $92(10.6)$ & & \\
\hline Absent & $100(75.2)$ & $778(89.4)$ & & \\
\hline \multicolumn{5}{|l|}{ Method chosen in current suicide attempt } \\
\hline Drug overdose or chemical ${ }^{*}$ ingestion & $103(77.4)$ & $675(77.6)$ & 0.00 & 0.524 \\
\hline Cut & $18(13.5)$ & $115(13.2)$ & 0.01 & 0.505 \\
\hline Jump & $2(1.5)$ & $16(1.8)$ & 0.07 & 0.565 \\
\hline Hanging & $3(2.3)$ & $38(4.4)$ & 1.31 & 0.183 \\
\hline Traffic & $1(0.8)$ & $2(0.2)$ & 1.05 & 0.348 \\
\hline Carbon monoxide intoxication & $6(4.5)$ & $17(2.0)$ & 3.37 & 0.072 \\
\hline Others & $7(5.3)$ & $35(3.5)$ & 0.44 & 0.318 \\
\hline Numbers of lifetime suicide attempts & $1.4 \pm 0.8$ & $1.7 \pm 1.3$ & 2.59 & 0.010 \\
\hline
\end{tabular}

Values are presented as mean \pm standard deviation or number (\%).

*Include herbicide, pesticide, detergent, oil, acid, alkali and other non-edible chemicals.

Table 4. Risk factors predicting planned suicide attempts

\begin{tabular}{|c|c|c|c|c|c|}
\hline \multirow{2}{*}{ Variable } & \multirow{2}{*}{ B } & \multirow{2}{*}{$\operatorname{Exp}(B)$} & \multicolumn{2}{|c|}{$95 \% \mathrm{Cl}$ for $\operatorname{Exp}(\mathrm{B})$} & \multirow{2}{*}{$p$ value } \\
\hline & & & Lower & Upper & \\
\hline Suicide for what (hope to die) & 1.99 & 7.29 & 4.52 & 11.76 & $<0.001$ \\
\hline Presence of will & 1.49 & 4.42 & 2.76 & 7.08 & $<0.001$ \\
\hline Suicide idea (repetitive/intense/continuous) & 1.38 & 3.98 & 2.29 & 6.91 & $<0.001$ \\
\hline Numbers of lifetime suicide attempts & -0.46 & 0.63 & 0.47 & 0.84 & 0.001 \\
\hline Total scores of rescue rating & -0.22 & 0.80 & 0.72 & 0.90 & $<0.001$ \\
\hline
\end{tabular}

95\% Cl, 95\% confidence interval.

ods of obtaining information regarding suicide plans. Community population-based studies often report a high frequency of planned suicide attempts, ${ }^{15,30)}$ which is likely because these studies assess the presence of suicidal plans and attempts separately from the point of interview. Thus, it may be possible that the suicide plan was not made proximal to the attempt. ${ }^{18)}$ In the present study, the planning of the index attempt could be obtained in a relevant manner 
by obtaining information from the patients who immediately visit the ED after a suicide attempt.

The planned SA group was more likely to be diagnosed with major depressive disorder than the impulsive SA group, which is consistent with the findings of previous studies. ${ }^{7,31,32)}$ However, there were no significant differences in the prevalence of bipolar depression, which is quite different from the findings of a previous study that revealed the relative risk of bipolar disorder to be 3.5 times higher in unplanned (impulsive) SAs than in planned SAs. ${ }^{15)}$ Additionally, contrary to the findings of previous studies, ${ }^{30,33)}$ the present study showed that planned SAs were more likely to have alcohol or other substance use disorders than impulsive SAs. Although there are several explanations for these discrepancies, including the utilization of different populations, diagnostic methods, and cultural factors, further studies are necessary to clarify these differences. In the present study, the presence of an adjustment disorder was more frequent in impulsive SAs than in planned SAs. Because impulsive SAs often experience stressful events prior to a suicide attempt ${ }^{10,34)}$ and because adjustment disorder can be defined as the experience of emotional and behavioral problems in response to identifiable stressors, ${ }^{35}$ the present findings are plausible.

Consistent with the findings of previous studies, ${ }^{9)}$ planned SAs were older than impulsive SAs and tended to be divorced, separated, or widowed. However, there are limited prior data regarding marital status in planned SAs and several studies have failed to find significant differences between planned and impulsive SAs. ${ }^{15,31)}$ With respect to clinical factors, the present study found that there was a higher comorbidity of medical issues in planned SAs. A previous study from our research group showed that medical illnesses were the most common reason for suicide in elderly SAs, exhibiting a higher level of lethality, ${ }^{23)}$ which may be in line with the present findings.

It is noteworthy that the planned SAs in the present study had more financial problems and physical illnesses than the impulsive SAs, because these stressors are related to successful suicide. ${ }^{36)}$ The higher tendency for choosing $\mathrm{CO}$ intoxication in the planned SA group was also indicative of their increased risk for a completed suicide because this method is highly lethal. ${ }^{37)}$ Previous studies have shown that there is a higher lethality in planned suicide groups ${ }^{8,38)}$ and, thus, it is important to identify the predictors of individuals who are vulnerable for planned suicide attempts in order to prevent these actions.

Agitation, hopelessness, helplessness, and self-blaming tendencies were more frequently identified in planned
SAs than in impulsive SAs in the present study. Therefore, the intent of planned SAs was more likely to reflect a hope for death rather than a change in their circumstances. Based on these results, the intent to die was a significant predictor for planned suicide attempts as well as for other factors such as the presence of will and a higher severity of suicidal ideation. Because a risk-recognition strategy has been proposed as an effective method for preventing planned suicide attempts, ${ }^{39)}$ the predicting factors identified in the present and previous studies may be useful.

However, the present study also indicated that recognizing risks may not be that simple because planned SAs were active participants in the suicidal process and showed a tendency to not signal for rescue. Moreover, consistent with previous studies, ${ }^{8,40)}$ planned SAs in the present study had a fewer number of lifetime suicide attempts compared to the impulsive SA group, and a previous study has shown that the suicidal behavior of planned SAs tends to progress rapidly from ideation to attempt. ${ }^{15)}$ These findings suggest that the close observation of these individuals and the early recognition of risk factors are important because early interventions could result in a better chance of preventing serious suicide attempts. Thus, primary caregivers, including primary physicians or family members, play an important role in preventive strategies and should be trained as gatekeepers.

In the present study, impulsive SAs were more likely to hope for change and to suffer from interpersonal conflicts. Despite the fact that impulsive SAs had a low intent for death and lethality, repetitive suicidal behaviors in this population may be another serious problem. Considering the nature of intent, which has been reported as reflecting tension-reducing or -escaping strategies in this group, ${ }^{40,41)}$ the provision of interpersonal coping strategies and other suicide prevention techniques will be important.

The present study has several limitations that must be mentioned. First, subjects were not included if they were not able to participate in the psychiatric interviews due to serious medical conditions or did not have an accompanying informant. This may have resulted in a selection bias due to the underrepresentation of more lethal attempters with poor familial and/or social support. Second, because the psychiatric interviews and evaluations were conducted in a busy emergency room when the patients were in an unstable condition immediately after attempting suicide, the presence of psychological disturbances may have been over-represented. Finally, Axis II diagnoses were not included, which is important because patients with borderline personality disorder may have higher impulsivity that could 
significantly contribute to impulsive suicide attempts. The Axis II diagnoses were not included in the present study because a brief interview in the ED with few subjects may result in misdiagnoses and biases. Nonetheless, the present findings may shed more light on the understanding of suicidal behavior because the present study included a large sample size and the data was obtained in the ED by trained psychiatric doctors immediately after the suicide attempt.

In conclusion, the present study demonstrated that planned SAs were older and more likely to be divorced, separated, or widowed. Additionally, this group had more severe clinical profiles in terms of precipitating stressors than did the impulsive SA group.

\section{REFERENCES}

1. Chishti P, Stone DH, Corcoran P, Williamson E, Petridou E; EUROSAVE Working Group. Suicide mortality in the European Union. Eur J Public Health 2003;13:108-114.

2. Sharma BR, Gupta M, Sharma AK, Sharma S, Gupta N, Relhan $\mathrm{N}$, et al. Suicides in Northern India: comparison of trends and review of literature. $J$ Forensic Leg Med 2007; 14:318-326.

3. Chang YS. The comparison of mortality rate by causes of death in OECD countries. Issue Focus 2014;(257):1-8.

4. Beck AT, Lester D. Components of suicidal intent in completed and attempted suicides. J Psychol 1976;92:35-38.

5. Thompson AH, Dewa CS, Phare S. The suicidal process: age of onset and severity of suicidal behaviour. Soc Psychiatry Psychiatr Epidemiol 2012:47:1263-1269.

6. Conner KR. A call for research on planned vs. unplanned suicidal behavior. Suicide Life Threat Behav 2004:34:89-98.

7. Brown LK, Overholser J, Spirito A, Fritz GK. The correlates of planning in adolescent suicide attempts. J Am Acad Child Adolesc Psychiatry 1991;30:95-99.

8. Baca-García E, Diaz-Sastre C, Basurte E, Prieto R, Ceverino A, Saiz-Ruiz J, et al. A prospective study of the paradoxical relationship between impulsivity and lethality of suicide attempts. J Clin Psychiatry 2001;62:560-564.

9. Hamdi E, Amin Y, Mattar T. Clinical correlates of intent in attempted suicide. Acta Psychiatr Scand 1991;83:406-411.

10. Zhang J, Xu H. Degree of suicide intent and the lethality of means employed: a study of Chinese attempters. Arch Suicide Res 2007;11:343-350.

11. Conner KR, Hesselbrock VM, Meldrum SC, Schuckit MA, Bucholz KK, Gamble SA, et al. Transitions to, and correlates of, suicidal ideation, plans, and unplanned and planned suicide attempts among 3,729 men and women with alcohol dependence. J Stud Alcohol Drugs 2007;68:654-662.

12. Weyrauch KF, Roy-Byrne P, Katon W, Wilson L. Stressful life events and impulsiveness in failed suicide. Suicide Life Threat Behav 2001;31:311-319.

13. Hjelmeland H, Nordvik H, Bille-Brahe U, De Leo D, Kerkhof JF, Lönnqvist J, et al. A cross-cultural study of suicide intent in parasuicide patients. Suicide Life Threat Behav 2000;30:295-303

14. Fedyszyn IE, Harris MG, Robinson J, Edwards J, Paxton SJ. Characteristics of suicide attempts in young people undergoing treatment for first episode psychosis. Aust N Z $J$ Psychiatry 2011;45:838-845.

15. Jeon HJ, Lee JY, Lee YM, Hong JP, Won SH, Cho SJ, et al. Unplanned versus planned suicide attempters, precipitants, methods, and an association with mental disorders in a Korea-based community sample. J Affect Disord 2010;127: 274-280.

16. Borges G, Saltijeral MT, Bimbela A, Mondragón L. Suicide attempts in a sample of patients from a general hospital. Arch Med Res 2000;31:366-372.

17. Joe S, Baser RE, Breeden G, Neighbors HW, Jackson JS. Prevalence of and risk factors for lifetime suicide attempts among blacks in the United States. JAMA 2006;296:21122123.

18. Rimkeviciene J, O'Gorman J, De Leo D. Impulsive suicide attempts: a systematic literature review of definitions, characteristics and risk factors. J Affect Disord 2015;171:93-104.

19. Granboulan V, Roudot-Thoraval F, Lemerle S, Alvin P. Predictive factors of post-discharge follow-up care among adolescent suicide attempters. Acta Psychiatr Scand 2001;104:31-36.

20. Chesin MS, Jeglic EL, Stanley B. Pathways to high-lethality suicide attempts in individuals with borderline personality disorder. Arch Suicide Res 2010;14:342-362.

21. Deisenhammer EA, Ing CM, Strauss R, Kemmler G, Hinterhuber H, Weiss EM. The duration of the suicidal process: how much time is left for intervention between consideration and accomplishment of a suicide attempt? $J$ Clin Psychiatry 2009;70:19-24.

22. Kweon YS, Hwang S, Yeon B, Choi KH, Oh Y, Lee HK, et al. Characteristics of drug overdose in young suicide attempters. Clin Psychopharmacol Neurosci 2012;10:180184.

23. Choi JW, Park S, Yi KK, Hong JP. Suicide mortality of suicide attempt patients discharged from emergency room, nonsuicidal psychiatric patients discharged from emergency room, admitted suicide attempt patients, and admitted nonsuicidal psychiatric patients. Suicide Life Threat Behav 2012:42:235-243

24. Choi KH, Wang SM, Yeon B, Suh SY, Oh Y, Lee HK, et al. Risk and protective factors predicting multiple suicide attempts. Psychiatry Res 2013;210:957-961.

25. Misson H, Mathieu F, Jollant F, Yon L, Guillaume S, Parmentier C, et al. Factor analyses of the Suicidal Intent Scale (SIS) and the Risk-Rescue Rating Scale (RRRS): toward the identification of homogeneous subgroups of suicidal behaviors. J Affect Disord 2010;121:80-87.

26. Weisman $\mathrm{AD}$, Worden JW. Risk-rescue rating in suicide assessment. Arch Gen Psychiatry 1972;26:553-560.

27. Baca-Garcia E, Diaz-Sastre C, García Resa E, Blasco H, Braquehais Conesa D, Oquendo MA, et al. Suicide attempts and impulsivity. Eur Arch Psychiatry Clin Neurosci 2005;255:152-156.

28. Hawton K, Simkin S, Gunnell D, Sutton L, Bennewith O, Turnbull $\mathrm{P}$, et al. A multicentre study of coproxamol poisoning suicides based on coroners' records in England. Br J Clin Pharmacol 2005;59:207-212.

29. Joe S, Canetto SS, Romer D. Advancing prevention research on the role of culture in suicide prevention. Suicide Life Threat Behav 2008;38:354-362.

30. Bagge CL, Littlefield AK, Lee HJ. Correlates of proximal premeditation among recently hospitalized suicide attempters. $J$ Affect Disord 2013;150:559-564.

31. Simon OR, Swann AC, Powell KE, Potter LB, Kresnow MJ, O'Carroll PW. Characteristics of impulsive suicide attempts and attempters. Suicide Life Threat Behav 2001;32(1 Suppl):49-59.

32. Wyder M, De Leo D. Behind impulsive suicide attempts: 
indications from a community study. J Affect Disord 2007; 104:167-173.

33. Spokas M, Wenzel A, Brown GK, Beck AT. Characteristics of individuals who make impulsive suicide attempts. J Affect Disord 2012;136:1121-1125.

34. Banwari GH, Vankar GK, Parikh MN. Comparison of suicide attempts in schizophrenia and major depressive disorder: an exploratory study. Asia Pac Psychiatry 2013;5: 309-315.

35. American Psychiatric Association. Diagnostic criteria from DSM-IV-TR. Washington, DC:American Psychiatric Pub; 2000.

36. Park S, Choi JW, Kyoung Yi K, Hong JP. Suicide mortality and risk factors in the 12 months after discharge from psychiatric inpatient care in Korea: 1989-2006. Psychiatry Res 2013;208:145-150.
37. Rhyne CE, Templer DI, Brown LG, Peters NB. Dimensions of suicide: perceptions of lethality, time, and agony. Suicide Life Threat Behav 1995;25:373-380.

38. Mann JJ, Malone KM, Sweeney JA, Brown RP, Linnoila M, Stanley B, et al. Attempted suicide characteristics and cerebrospinal fluid amine metabolites in depressed inpatients. Neuropsychopharmacology 1996;15:576-586.

39. Mann JJ, Apter A, Bertolote J, Beautrais A, Currier D, Haas A, et al. Suicide prevention strategies: a systematic review. JAMA 2005;294:2064-2074.

40. Williams CL, Davidson JA, Montgomery I. Impulsive suicidal behavior. J Clin Psychol 1980;36:90-94.

41. Cornelius JR, Salloum IM, Day NL, Thase ME, Mann JJ. Patterns of suicidality and alcohol use in alcoholics with major depression. Alcohol Clin Exp Res 1996;20:1451-1455. 